\title{
The Influence Of Attitudes And Experience On The Owner-Manager's Intentions Towards Cooperation
}

Manuel Haug, Albstadt-Sigmaringen University, Germany Lutz Sommer, Albstadt-Sigmaringen University, Germany

\begin{abstract}
The goal of this paper is to shed some light on how attitudes of owner-managers and entrepreneurs respectively influence a company's cooperative behaviour. The focus is hereby on how the decision-makers' attitudes toward the possible reasons for setting up a cooperation influence the intended intensity of the cooperative arrangement. This research question is investigated on the basis of empirical data gathered from Mexican SME. As a result, both motivations for cooperation and experiences with cooperative arrangements in the past seem to influence the intended intensity of future activities.
\end{abstract}

Keywords: SME, attitudes, cooperation, cooperation intensity

\section{INTRODUCTION}

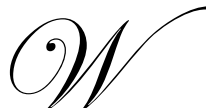

hile many large companies all over the world are very often seen as the spearhead of the globalized world's economy, Small and Medium Sized Enterprises play an important role as well - in certain aspects, their relevance may be even higher than that of large Multinational Companies (MNC). For example, Beck et al. (2005) found a strong positive association between the relative strength of an economy's SME sector and the Gross Domestic Product per capita growth.

Without any doubt globalization is currently the most important development for economies all over the world, and it directly influences SME, even if they are not active in others as their domestic markets. While globalization surely entails several positive effects - such as new markets, the possibility to profit from lower labor costs in abroad, and others - it also induces new challenges as it enables companies from all over the world to sell their products worldwide. Thus, globalization allows companies to find and enter new markets - i.e. be an active player in the so-called international arena -, and as a result to raise their revenues and profits, but it also intensifies competition. Each company has to make large efforts in order to be competitive: reduce costs, improve organisational structures, be innovative, and others.

While large companies very often react effectively and efficiently to the pressure globalization causes, Small and Medium Sized Enterprises (SME) face a lot of problems. The barriers to overcome when planning and implementing their internationalization are generally much more serious for SME than for large companies (Acs/Preston 1997). A general constraint especially for small companies is the number and variety of their resources being rather small and narrow (Jarillo 1989), respectively. To resolve these problems co-operation could be an appropriate means and especially for SME, internationalization by co-operation (Perlitz/Seger 2003; Kirby/Kaiser 2003) seems to be a promising strategy. There is of course a wide range of possible forms of co-operation, ranging from informal meetings to legally independent companies - Joint Ventures (Ringlstetter 1997, p. 50 et seqq.).

Inter-firm cooperation has been discussed for more than two decades now, but special attention to this issue has been paid in recent years (Hartl 2003). The research available so far covers aspects such as organizational and environmental characteristics. Furthermore, managerial issues - e.g. strategy or relationship management - have 
been addressed. Also, researchers investigated the effects of external networks, e.g. performance issues or the role of competitive advantages (Street/Cameron 2007, p. 243).

The goal of this paper is to shed some light on how attitudes of owner-managers and entrepreneurs respectively influence a company's cooperative behaviour. The focus is hereby on how the decision-makers' attitudes toward the possible reasons for setting up a cooperation influence the intended intensity of the cooperative arrangement. In order to investigate this research question, empirical data from a survey conducted in Mexico (Sommer/Reiband 2006) are used.

This paper proceeds as follows. In the next section, a literature review and the hypotheses are presented. This section is followed by a brief overview on the methodology. The results of the conducted survey are presented in section 4, while section 5 features an in-depth discussion of the results using analytical methods. Conclusions, managerial implications, and limitations of the research are presented in the last section.

\section{LITERATURE REVIEW}

\section{Role Of SME In Today's Economies}

The importance of SME for today's economies cannot be overstated. The share of SME in the total number of companies in the economy is between 96 and 99\% in most OECD countries. In Europe, more than $99 \%$ of companies are small and medium-sized businesses. The European Commission states that "SME play a decisive role in job creation and exports and act as a factor of social stability and economic drive [...]" (European Commission 1998). Not surprisingly, Small and medium-sized businesses play a very important role when it comes to strengthening the economic output of an economy. They are responsible for a significant share of the economic output, in the US for example they account for about $40 \%$ of the total gross domestic product. Furthermore, in recent years, they are responsible for the vast majority of new businesses; this is especially true for the United States (OECD 2002, p. 7 et. seqq.)

Another important figure is the number of employments. SME' contribution to the overall employment is between 60 and $70 \%$ of the manufacturing total in most OECD countries; similarly in the service sector, they account for the vast majority of jobs. This relatively high importance of SME for the overall employment becomes even more interesting if one has a look at the creation of new employments. Where large companies more and more seem to reduce their staff, the rates of gross job creation by SME is significantly higher than the one by large firms (OECD 2002, p. 7). There seems to be a clear negative relationship between company size and net job creation rates (Schreyer 1996). In the 1990s in both the US and the EU, small firms were responsible for a great share of employment growth (OECD 2002, p. 8). In EU25, SME of the non-financial sector had the greatest net job creation rate (Eurostat 2006, p. 1). Similarly, between 1999 and 2002, small businesses were the main engine for job creation in China (Yin 2005). Also, SME are an important source for innovation. Looking more closely at the OECD manufacturing sector, one can see that 30 to $60 \%$ of businesses can be seen as innovative. Summing up these figures, one can says that SME "are the backbone of virtually all economies in the world" (Wattanapruttipaisan 2003, p. 66).

\section{Cooperation As Strategy To Deal With Stress Of Competition}

While SME seem to play a crucial for many economies around the world, they nevertheless have several weaknesses when compared to large companies. As globalization implies - among other things - rapid changes in economy and constantly harder production and trade frameworks (ENSR 2003, p. 10), this development entails a lot of challenges for SME. They have to react to competition by adjusting their organisational structure and adopting new technologies, what causes costs. SME frequently show a lack of both capital and human resources - recent research showed that this is even true for managerial skills (OECD 2002, pp. 13 et seqq.). In this situation, participating in cooperative arrangements with other companies has a lot of benefits, such as broadening the resource base in terms of skills, technologies, and know-how, possibility of risk-sharing, combining complementary 
capabilities and profiting from economies of scale in order to withstand the pressure induced by large companies (Hartl 2003; Narayanan 2000; Silverman/Baum 2002).

This paper focuses on how attitudes of entrepreneurs and owner-managers influence the intensity of cooperation to be set up. In order to clarify how this work is embedded in existing research, the framework defined by Street and Cameron (2007) is used. They conducted a review of publications with respect to external relationships of a small company. In order to categorize the contributions in this field, they made use of a three component framework distinguishing the antecedents, processes and outcomes of external relationships such as alliances. Their detailed framework is given below:

\begin{tabular}{|c|c|c|}
\hline $\begin{array}{l}\text { Individual Characteristics } \\
\text { Of the entrepreneur } \\
\text { Of the manager }\end{array}$ & $\begin{array}{l}\text { Strategy Development and } \\
\text { Planning }\end{array}$ & $\begin{array}{l}\text { Organizational Development } \\
\text { Access to Resources } \\
\text { Business Development }\end{array}$ \\
\hline $\begin{array}{l}\text { Organizational } \\
\text { Characteristics } \\
\text { Of the SME }\end{array}$ & $\begin{array}{l}\text { Relationship Formation } \\
\text { Active participation } \\
\text { Trust \& Relationship Building }\end{array}$ & $\begin{array}{l}\text { Competition and } \\
\text { Competitive Advantage }\end{array}$ \\
\hline & 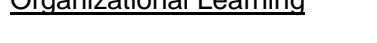 & Performance/Success \\
\hline Relationship Characteristics & & $\frac{\text { Objective and Subjective }}{\text { Performance }}$ \\
\hline Environmental & & $\frac{\text { Success in terms of a Stated }}{\text { Goal }}$ \\
\hline
\end{tabular}

Figure 1 - Conceptual Model of External Relationship Antecedents, Proceses, and Results Source: modified according to Street/Cameron 2007, p. 243

Based on this approach, one can see that the topic of this paper relates to the "Antecedents" component, which consists of four main fields: individual traits, organizational characteristics, relationship and environmental characteristics $^{1}$. The first subcategory - i.e. individual characteristics - is of particular interest as it deals explicitly with "the owner and/or entrepreneur, small business managers [...]" characteristics (Street/Cameron 2007, p. 243.). Individual characteristics refer to "decision maker attitudes and predispositions towards cooperation" (Schermerhorn 1975, p. 853).

So far, several characteristics have been examined. Among them are - not surprisingly - ethnicity and gender (Alizadeh 1998; Moore/Moore 1999). Furthermore, family roots (Renzulli et al. 2000), cultural influences (Oughton/Whitman 1997; Elo 2003), and the role of personal networks (Dodd et al. 2002) have been investigated. For some researchers, one's personal character also seemed to be relevant (Young/Olk 1997). There are also studies with respect to personal traits which are more related to the business world, such as entrepreneurial orientation (Weaver/Dickson 1997), experience (Bruderl et al. 1992), and willingness to learn (Beecham/Cordey-Hayes 1998). Trust represents another important field in the context of personal characteristics, several studies are available (e.g. Volery/Mensik 1998; Rus/Iglic 2005; Kocak/Edwards 2005; Fink/Kraus 2007). Taking into consideration the geographical focus of this paper, i.e. Mexico, a study by Kühlmann (2004) should be mentioned, as he conducted a survey among Mexican and German SME commonly participating in cross-border cooperation. He found that the investigated cooperative arrangements are characterized by a high level of mutual trust. Nevertheless, Mexican partners seem to have more trust in their German partners than vice versa. For German SME, building up and

\footnotetext{
${ }^{1}$ Hartl (2003) follows a similar approach, though his framework only deals with circumstances that lead enterprises to cooperate, i.e. his analysis is focused on the above mentioned "Antecedents". He outlines, that there are three different approaches, i.e. Industry-specific characteristics, structural characteristics of the enterprise, and personal characteristics of the entrepreneur.
} 
fostering interpersonal relationships seem to be the preferred strategy whereas the Mexican are out to demonstrate honesty, competence, and reliableness.

Another individual characteristic not mentioned so far is represented by the attitudes an owner-manger may have toward a certain object. Fishbein and Ajzen (1975) define attitude as feelings - positive or negative - about objects or people; in our case, of course, attitude toward cooperative strategies or - more precisely - motivations for cooperation are meant. A manager's decisions about participating in cooperation are influenced by internal and external factors. Given the manager's individual background it is likely that this background - and thus also attitudinal aspects being an element of the manager's self - influence his decisions on cooperative behaviour. Legoherél et al. (2004) found that attitudinal components have an impact on "the outwardness/inwardness of the firm (related to the manager's profile)" (Legoherél et al. 2004, p. 118).

As for attitudinal considerations which explicitly refer to cooperation, the research work so far seems to be rather thin. Among the first to investigate this particular field were Pollnac and Carmo (1980) who focused on smallscale fishermen and farmers in the Azores. They compared attitudes toward cooperation and the degree to which these people actually participated in cooperative organizations. They examined this research question by looking on the variances of cooperation attitude and cooperation behaviour with respect to certain sociocultural variables. Human and Provan (1997) presented a model for SME network structures and outcomes; in the course of their research which aimed at shading light on the structure and performance of SME networks, they explicitly addressed the matter of what attitudes entrepreneurs and managers have toward cooperation with competitors. "The evidence indicates that the exchanges, organizational credibility, and access to resources available to firms through the networks were not pursued through interorganizational relationships by market firms" (Human/Provan 1997, p. 387). Beecham/Cordey-Hayes (1998) investigated technology partnering arrangements in the UK automotive industry. The focus of their work was on managerial attitudes within SME toward certain forms of partnering arrangements. They found that attitudes toward partnering influence knowledge transfer. Another important contribution to this field of research was made by Froehlich and Pichler (1998) who suggested different entrepreneurial types based on attitudinal considerations. The "Pioneer" is risk taking, open to changes whereas the "Organizer" - the title being telltale - is endued with administrative-executive skills. The former seems to be more open to cooperative arrangements. The authors eventually provide some evidence for distinct entrepreneurial types influencing the decision making process. A related paper by Pichler and Voithofer (2000) examines patterns of SME cooperation, strategic alliances, and networking. They focused on entrepreneurial attitudes and behavioural patterns in order to clarify how entrepreneurs react when confronted with environmental challenges such as market enlargement as consequence of new countries accessing the European Union. Their purpose was to identify entrepreneurial types who are able to deal with such "external shocks". Their research work yielded evidence that there are different types of entrepreneurs and that the latter can be distinguished according to attitudes toward cooperation and networking. A cross-country study on attitudes toward cooperative strategies has been done by Steensma et al. (2000). They developed nine hypotheses in order to explore cultural influences on attitudes toward cooperation. These covered masculinity - which according to Hofstede (1991) could serve as a distinctive feature for cultures -, uncertainty avoidance - as again according to Hofstede (1980) societies vary in their estimation of ambiguity and risk -, and individualism, because societies differ in terms of the relative importance of individual pursuits as compared to collective pursuits (Hofstede 1991). The authors found that entrepreneurs from more masculine and individualistic oriented societies are not as open to cooperation as their counterparts from feminine and collectivist cultures. It can be assumed that masculine societies perceive cooperation strategies rather as a consequence of an entrepreneur's or the company's weakness. Furthermore, independence and control are highly estimated in individualistic cultural environments. Based on this work, another study by Marino et al. (2002) explicitly addressed the question whether there is a relationship between entrepreneurial orientation and Strategic Alliance Portfolio (SAP) Extensiveness. The results were similar to the aforementioned study as it turned out that "entrepreneurial SME from cultures with higher levels of individualism and masculinity will be less likely to leverage the benefits associated with SAP extensiveness than their counterparts from more collectivist or feminine cultures" (Marino et al. 2002, p. 158). Lohrke et al. (2006) investigated a set of SME in order to gain insight in how current performance levels might influence the cooperative behaviour of an SME. Within the framework of their study which is based on behavioural theory of the firm and threat rigid thesis, they developed some hypotheses dealing with the impact of performance dissatisfaction on the intention to participate in alliances in future. These 
hypotheses distinguish between firms already participating in alliances and those not yet involved in such cooperative arrangements. The study revealed that performance dissatisfaction seems to be an important variable, showing strong effects on manager's alliance formation intentions. In other words, the way a manager perceives his firm's performance has an effect on his attitude toward participating in an alliance. Brunetto and Farr-Wharton (2007) examined the role trust in a SME owner-manager's decision-making in terms of collaboration. Based on the assumptions that so far there have been identified two different kinds of networks - which are either explorative or exploitative in nature - they suggest the invention of a third, the so-called embryo-explorative network. The way owner-manager "vote" for the participation in a certain network type depends - among other factors - on trust. The finding suggest "that trust variables affect the way SME owner-managers perceive the potential benefits of participating in a network" (Brunetto/Farr-Wharton 2007, p. 382). Thus, trust seems to have an influence on ownermanagers attitude towards the engagement in a cooperative arrangement. Please note that the "type of network"issue refers more to the nature of the collaboration, neither to the organisational form nor the intensity of the cooperation.

The studies available so far investigate different aspects of attitudinal aspects in terms of cooperation. The role of a SME owner-managers attitude towards the motivations of cooperative arrangements and their impact on the intensity the owner-managers wish future cooperation to have, seems to be underrepresented. Therefore, this papers explores whether attitudes toward certain motivations for cooperative strategies say something about the intensity these cooperation are likely to have. The research model on which the work is based is given in Figure 2.

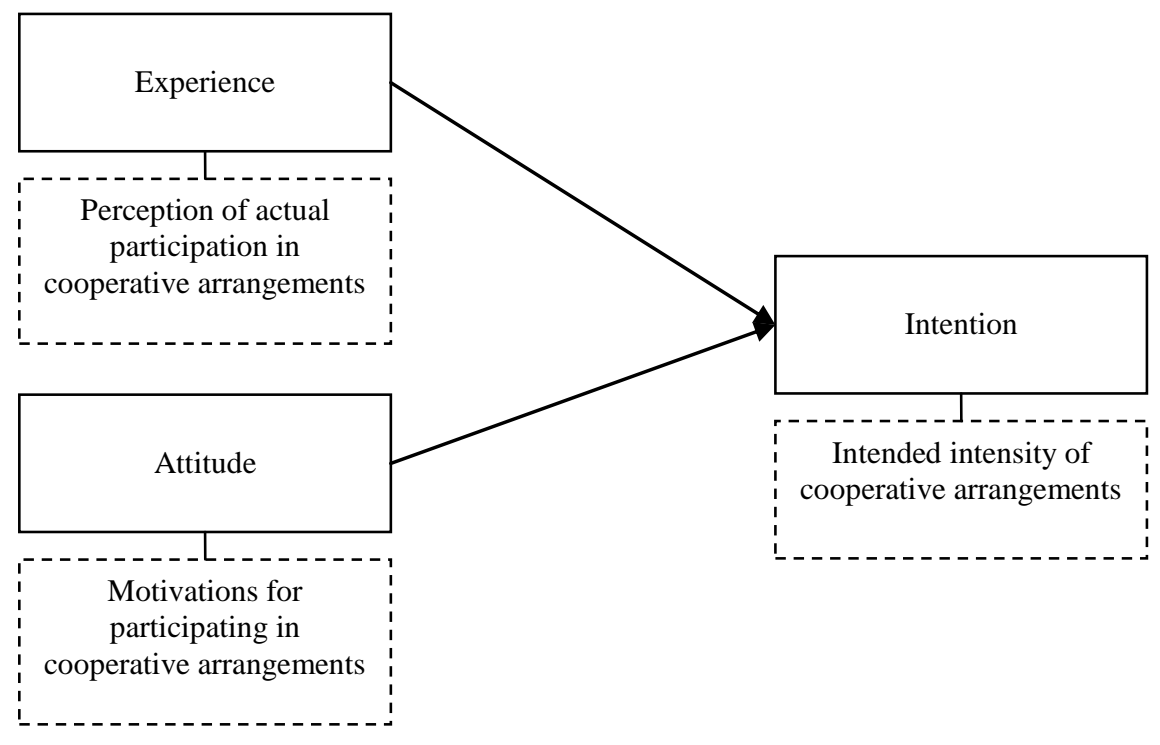

Figure 2 - Research model

Thus, the first hypothesis refers to the attitudinal component of the research model and is as follows:

H1: Owner-managers attitude toward motivations for cooperation influence the intensity future cooperation they are involved are likely to have.

Without any doubt, not only attitudes play a role when it comes to define the intensity of cooperative arrangement but also experiences from the past. Therefore, for those SME which are already experienced in terms of cooperation, this aspect will probably influence future decisions on how intense cooperation should be. This shall be tested by the second hypothesis: 
H2: The cooperation experience consisting of intensity of cooperation in the past and number of cooperation is a predictor for the intensity of future cooperative arrangements.

\section{METHODOLOGY}

\section{Sampling Frame}

In order to examine the above mentioned hypotheses a survey among Mexican SME has been conducted. Table 1 shows for each size category the share of all Mexican companies belonging to this category:

\begin{tabular}{|l|c|c|}
\hline & Industry & Services \\
\hline Micro companies & $94,40 \%$ & $94,90 \%$ \\
\hline Small companies & $3,70 \%$ & $4,00 \%$ \\
\hline Medium-sized companies & $1,70 \%$ & $0,90 \%$ \\
\hline Large companies & $0,40 \%$ & $0,20 \%$ \\
\hline
\end{tabular}

Table 1 - Company share in per cent

As the authors were especially interested in small and medium-sized companies, they abstained from depicting the exact distribution, as otherwise the sample would have an extremely high share of mirco-companies, whose contribution to the investigated topic would probably be rather low. The questionnaire was addressed to the owner-managers or managers, respectively, as the data necessary for the analysis in this paper have to depict the decision-maker's attitudes. The study was conducted in collaboration with BANCOMEXT, Mexico's National Foreign Trade Bank ${ }^{2}$. The companies addressed in the course of the survey were extracted from a BANCOMEXT database.

About 7,525 selected companies in Mexico were contacted by email. The procedure started on September, 15th 2005 and due date for completing the survey was November, 30th 2005. About 502 firms filled in the questionnaire. Because of inconsistencies and break-ups, 419 companies are included in the analysis, therefore the rate of return equals 5.6\%. For details of the study please see Sommer/Reiband (2006). For further details on the sample structure please see section 4.

\section{Measurements}

The questionnaire consisted of four different parts, the first representing the statistical part gathering data on firm size, share of foreign sales, and others. The second part contained some variables which describe the actual cooperation behaviour of those companies already participating in cooperative arrangements. The items include among others - number of cooperation and cooperative market entry strategies in abroad. Intensity - ranging from exchange of experiences to Joint Ventures - have been sampled in part three. On a four point scale, the intended intensity for future cooperation have been collected, for those companies actively participating in cooperation, data on the intensity of the existing arrangement were gathered, too. The motivations were gathered in part four. Here, the respondents were asked to mark their attitudes toward each motivation on a five-point scale (important to unimportant). The motivation part comprised a set of eleven questions, yielding a Cronbach's alpha value of 0.84 which is really good. Thus, the research model presented above is reflected in parts three and four. For participants in the automotive industry, there was a fifth part dealing with automotive specific issues; these were gathered for information purposes only.

The main results of the study are presented in Chapter 4 while the detailed comparison and discussion is left to chapter 5. To get more insight in the data we will calculate bi variate correlations using the Spearman Correlation Coefficient. Furthermore we will make use of multiple regression analysis.

\footnotetext{
${ }^{2}$ www.bancomext.com
} 


\section{RESULTS - DESCRIPTIVE ANALYSIS}

In this section, some results are presented in a more or less descriptive way. First, we will have a look on what kind of companies filled in the questionnaire. With respect to the company size, we can see from Figure 3 that by far the most interviewees represent small or medium sized enterprises, while some companies should be assigned - albeit scantly, as a closer look on the data shows - to the category of large companies.

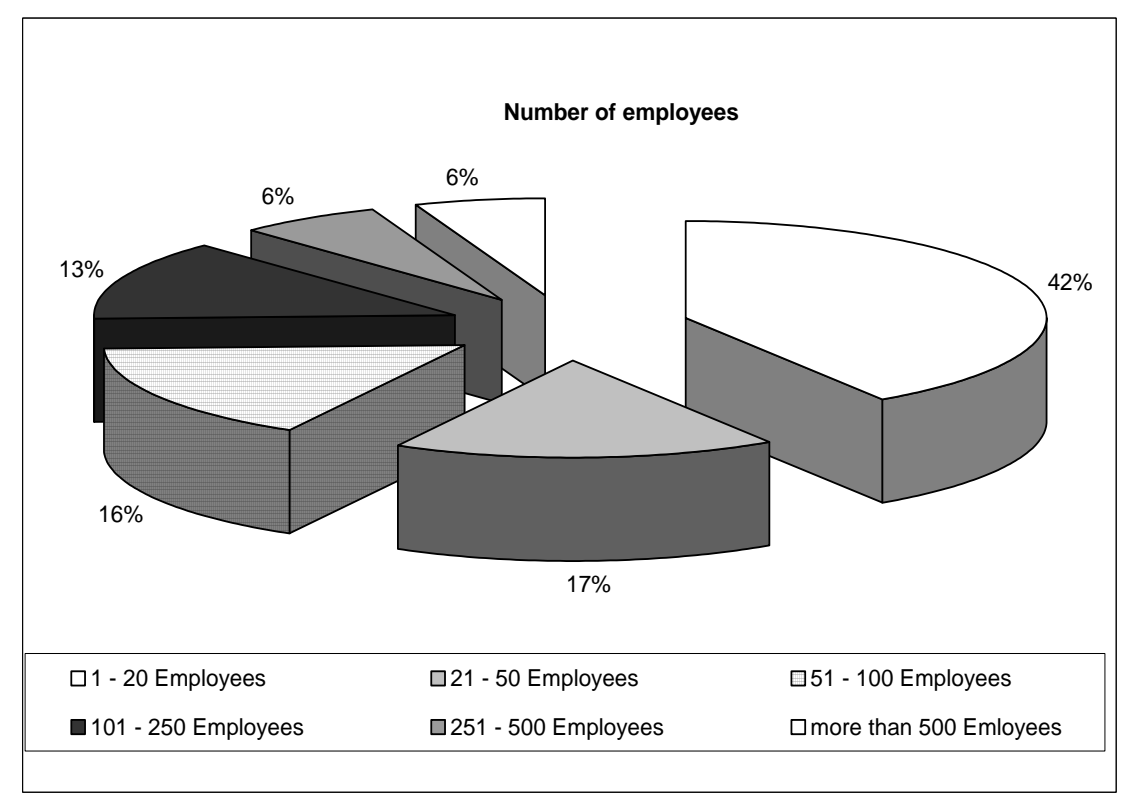

Figure 3 - Company size according to the number of employees

Figure 4 provides some insight in the companies' business activities, i.e. in which sector they are active. Please note, that for the statistical analysis in section 5, these industries have been aggregated to three main sectors, i.e. agriculture, industry, and services.

Please see table 2 for more information on which industry is assigned to which main sector.

\begin{tabular}{|c|c|c|}
\hline & Share & Main Sector \\
\hline Agriculture & $9,35 \%$ & \multirow{2}{*}{ Agriculture } \\
\hline Food & $5,61 \%$ & \\
\hline Machine building / Metal structure / Steel building & $16,12 \%$ & \multirow{3}{*}{ Industry } \\
\hline Automotive & $12,38 \%$ & \\
\hline Electronics & $4,44 \%$ & \\
\hline Chemistry / Plastics & $6,54 \%$ & \multirow{6}{*}{ Services } \\
\hline Commerce & $39,02 \%$ & \\
\hline Services & $2,10 \%$ & \\
\hline Construction & $3,27 \%$ & \\
\hline Information and communication technology & $0,70 \%$ & \\
\hline Tourism & $0,47 \%$ & \\
\hline
\end{tabular}

Table 2 - Assignment of industries to main sectors 
The following figures refer to the cooperation intensity. Figure 5 displays the intensity to which the respondents currently cooperate, Figure 6 shows the responding company's intentions in terms of future cooperation.

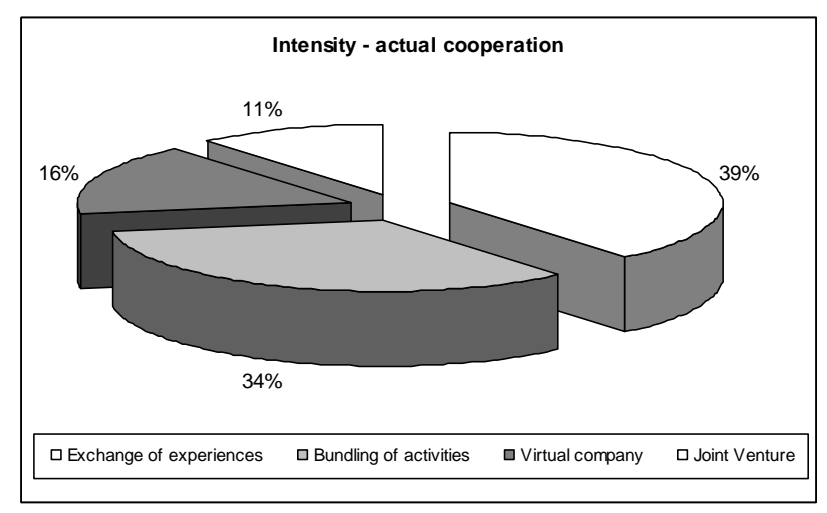

Figure 4 - Intensity of current cooperation

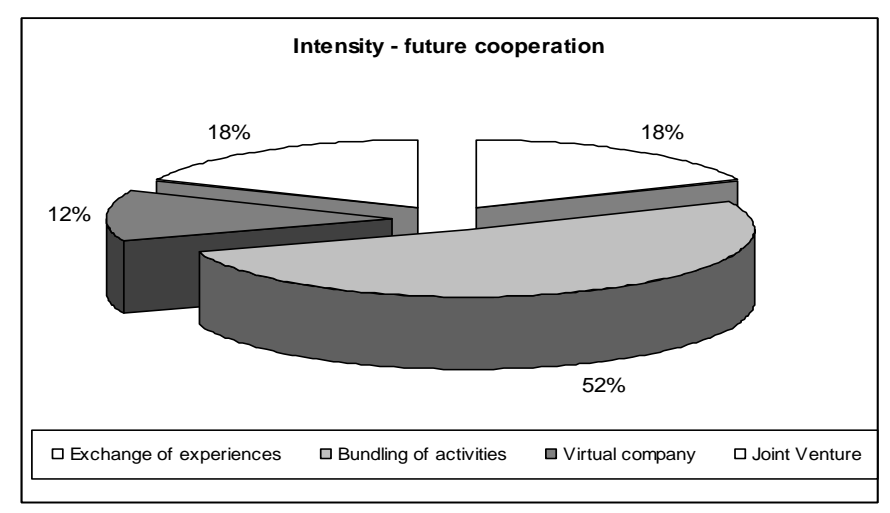

Figure 5 - Intended intensity of future cooperation

One can clearly see that while current cooperative arrangements are dominated by the lowest intensity, i.e. exchange of experiences, the future will see remarkable increases for two forms of intensities: bundling of activities and joint ventures. We will discuss implications of this observation in section 5.

As for the motivations, the respondents were asked to assess the importance from their individual point of view. Figure 7 displays six out of eleven motivations which show the highest values for rather important or important, respectively. Obviously, expansion oriented motivations - i.e. entering new markets, gain new distribution areas, and others - are of relatively high importance. In next section, we will have a look on how these attitudes influence owner-managers' intentions toward future cooperation intensity.

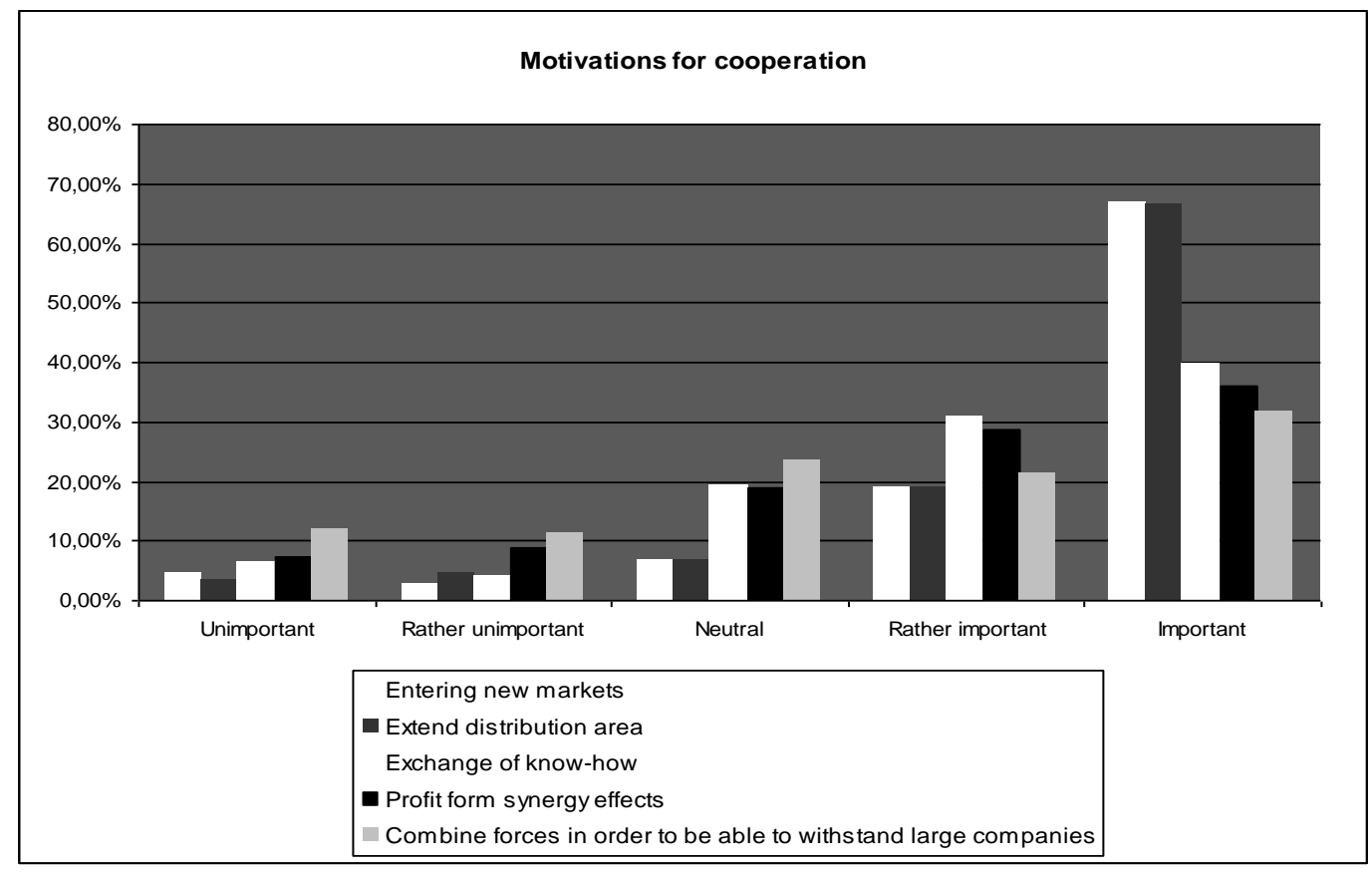

Figure 6- Importance of motivational aspects for cooperation 


\section{DISCUSSION}

All calculations in this section have been carried out with the statistical software SPSS 16. Also, the descriptive statistics presented in section 4 are calculated with the same tool.

\section{Hypothesis 1}

For testing hypothesis 1 , we used a multiple regression approach. The purpose was to assess the impact of the above mentioned motivation related variables on the dependent variable Q1137. The latter is represented by the intended intensity of future cooperation. As a first step, we included all of the independent variables - denominated as Q1139_0 thru Q1139_10 - in the model. Furthermore, firm size and industry occupation were used as control variables. For the model, we obtained an $\mathrm{R}^{2}$ value of 0.146 ; for the $\mathrm{F}$ statistic we got 2.056 , i.e. the model is significant at 0.020 , so basically this model could be used for further interpretation. Unfortunately, most coefficients - and the constant as well - proved to be not significant, two variables being the exception: "exchange of knowhow" (Q1139_4) - which yielded a standardized coefficient of $\beta=-0.251$ at $p<0.01$ and "combine forces in order to be able to withstand large companies" (Q1139_10) returning a $\beta$-value of 0.291 at $p<0.01$. Both coefficients are significant. In order to exclude the variables which do not contribute much to explain the dependent variable, we used the same set of variables as basis for a stepwise regression. The algorithm used the probability of $F$ value as stepping criteria with the entry probability equalling 0.05 and the probability for removal is at 0.1 . Not surprisingly, the $\mathrm{R}^{2}$ was even lower than before, amounting now to 0.104 . Interestingly, the algorithm yielded the same variables. Compared to the basic model containing only the control variables, we see a considerable increase of $\mathrm{R}^{2}$ of 9.6 points, being highly significant at 0.000 . So there is evidence that the above mentioned variables influence the intended future intensity of cooperation. In order to gain more insight into this issue, we carried out the stepwise regression once more, but now separately for those companies that haven't been involved in cooperation so far and those, who participated in at least one cooperative arrangement (for these companies, another variable was included, representing the intensity of actual cooperation Q1136). The results are given in table 3; the results for companies without cooperative experience are given in the first sub-table, the second one shows the computations for SME with at least one cooperation. The picture we got was much clearer now.

\begin{tabular}{|l|r|r|r|r|r|}
\hline & $\begin{array}{c}\text { Unstandardized } \\
\text { Coefficients }\end{array}$ & Std. Error & $\begin{array}{c}\text { Coefficients } \\
\text { Coefficients } \\
\text { Beta }\end{array}$ & $\mathrm{t}$ & \multicolumn{1}{c|}{ Sig. } \\
\hline (Constant) & 2,706 & 0,382 & & 7,082 & 0,000 \\
\hline Q1139_10 & 0,265 & 0,062 & 0,401 & 4,285 & 0,000 \\
\hline Q1139_4 & $-0,349$ & 0,083 & $-0,394$ & $-4,216$ & 0,000 \\
\hline
\end{tabular}

\begin{tabular}{|l|r|r|}
\hline $\mathrm{R}^{2}$ & 0.289 \\
\hline Adjusted $\mathrm{R}^{2}$ & 0.271 \\
\hline
\end{tabular}$\quad$\begin{tabular}{|l|r|}
\hline F & 16.633 \\
\hline
\end{tabular}

Companies not participating in cooperation

\begin{tabular}{|c|c|c|c|c|c|}
\hline \multicolumn{6}{|c|}{ Coefficients } \\
\hline & $\begin{array}{c}\text { Unstandardized } \\
\text { Coefficients } \\
\text { B }\end{array}$ & Std. Error & $\begin{array}{l}\text { Standardized } \\
\text { Coefficients } \\
\text { Beta }\end{array}$ & $\mathrm{t}$ & Sig. \\
\hline (Constant) & $\begin{array}{r}1,625 \\
\end{array}$ & 0,236 & & 6,881 & 0,000 \\
\hline Q1136 & 0,388 & 0,106 & 0,380 & 3,675 & 0,000 \\
\hline & $\mathrm{R}^{2}$ & 0.144 & & $F$ & 13.508 \\
\hline & Adjusted $\mathrm{R}^{2}$ & 0.134 & & Sig. & 0.000 \\
\hline
\end{tabular}

Companies participating in cooperation

Table 3 - Results of stepwise regression 
For companies with no experience in cooperation, the importance of variables Q1139_4 and Q1139_10 were confirmed, yielding a much higher $\mathrm{R}^{2}$ of 0.289 at $\mathrm{p}<0.001$. Interestingly, these results did not hold for the SME already participating in cooperation: for these companies, the algorithm yielded only one moderating variable, i.e. Q1136 representing the intensity of current cooperation. While the positive coefficient of Q1139_10 shows that the more important this motivation for SME, the higher the intended intensity, the relatively high value of the standardized beta coefficient indicates that this variable is of high relevance for the model. On the other hand, Q1139_4 has a negative coefficient suggesting that if SME assess know-how exchange rather high, they tend to strive for a lower intensity of future cooperation. The other motivational variables proved to have not enough predictable power for this research. Please note that we further discuss the findings for the group of SME already participating in cooperation in the next part.

We then tried to clarify whether not only cooperative experience but also the industry a company occupies influences the results of the multiple regression. In order to do so, we applied the algorithm once more to the data sets used in the previous step. Table 4 shows the computations; the coefficients depicted in the table are standardized values. Please note that the computations have been done for main sectors "Industry" and "Services" only, as the number of cases in the third main sector "Agriculture" was by far too low. Not surprisingly, the regressions support the evidence found in the analyses above. Please note that for cooperating SME active in the services main sector, another variable seem to have positive predictive power: Q1139_6, representing the motivation to share costs for investment with partners. For non-cooperating companies in the same main sector, also another variable seem to be promising, i.e. Q1139_1, which grasps the importance of extending the company's distribution area. The higher the importance of this variable is in the owner-mangers point of view, the lower the intensity of future cooperation tends to be. Please note that the respective regression model comprising now three predictors has a considerable $\mathrm{R}^{2}$ of 0.544 at $\mathrm{p}<0.001$.

\begin{tabular}{|c|c|c|c|c|}
\hline $\mathrm{R}^{2}$ & 0.311 & Variables & Coefficients & Sig. \\
\hline Adjusted R ${ }^{2}$ & 0.285 & Q1136 & 0,557 & 0,002 \\
\hline $\mathrm{F}$ & 12.174 & & & \\
\hline Sig. & 0.002 & & & \\
\hline $\mathrm{N}$ & 30 & & & \\
\hline \multicolumn{5}{|c|}{ Companies participating in cooperation / main Sector: Industry } \\
\hline $\mathrm{R}^{2}$ & 0.270 & Variables & Coefficients & Sig. \\
\hline Adjusted $\mathrm{R}^{2}$ & 0.285 & Q1139_6 & 0,345 & 0,022 \\
\hline $\mathrm{F}$ & 6.644 & Q1136 & 0,339 & 0,024 \\
\hline Sig. & 0.004 & & & \\
\hline $\mathrm{N}$ & 41 & & & \\
\hline \multicolumn{5}{|c|}{ Companies participating in cooperation / main Sector: Services } \\
\hline $\mathrm{R}^{2}$ & 0.161 & Variables & Coefficients & Sig. \\
\hline Adjusted $\mathrm{R}^{2}$ & 0.133 & Q1139_10 & $\begin{array}{r}0,402 \\
\end{array}$ & 0,023 \\
\hline $\mathrm{F}$ & 5.772 & & & \\
\hline Sig. & 0.023 & & & \\
\hline $\mathrm{N}$ & 33 & & & \\
\hline \multicolumn{5}{|c|}{ Companies not participating in cooperation / main Sector: Industry } \\
\hline $\mathrm{R}^{2}$ & 0.544 & Variables & Coefficients & Sig. \\
\hline Adjusted $\mathrm{R}^{2}$ & 0.504 & Q1139_4 & $-0,485$ & 0,000 \\
\hline $\mathrm{F}$ & 13.548 & Q1139_1 & $-0,383$ & 0,002 \\
\hline Sig. & 0.000 & Q1139_10 & 0,352 & 0,005 \\
\hline $\mathrm{N}$ & 41 & & & \\
\hline
\end{tabular}

Table 4 - Regression analysis separating cases by cooperation experience and main sector

Summarizing the results of this part, we can state that under certain conditions, variables related to motivations for cooperation seem to have predictive power in terms of the intended intensity for future cooperation. Basically, these predictions tend to be stronger for companies which are not engaged in cooperation so far. Much to 
our surprise, the predictive power of variables aiming at extending the companies sales volume or trading area, respectively, seem to be rather low. Please note that the predictive power of variables mentioned above is twofold: while e.g. Q1139_10 implies that the more important this motivation is, the higher the intended intensity for future cooperation is likely to be. On the other hand, the negative coefficients imply that a higher relevance of the particular motivation probably leads to a lower degree of future intensity. So Hypothesis 1 does not hold for all companies in our sample, therefore it should be rejected. Nevertheless, our findings strongly support H1 for certain variables and for a certain group of companies, i.e. those assigned to the services main sector. In this particular group, $\mathrm{H} 1$ especially holds for SME not involved in cooperation so far.

\section{Hypothesis 2}

In order to investigate Hypothesis 2 we first have a look at some descriptive methods. For testing $\mathrm{H} 2$ we introduce an additional variable: Q1134, which grasps the number of cooperation the respective company is involved.

We start by applying correlation analysis to Q1134 and Q1137 to examine whether the number of cooperation a SME is participating in is correlated with the intended cooperation intensity. The results are given in Figure 7.

\begin{tabular}{|l|l|l|r|r|}
\hline \multicolumn{5}{|c|}{ Correlations } \\
\hline \multirow{4}{*}{ Spearman's rho } & \multicolumn{1}{c|}{ Q1137 } & \multicolumn{1}{c|}{ Q1134 } \\
\cline { 2 - 5 } & Q1137 & Correlation Coefficient & 1,000 & 0,070 \\
\cline { 2 - 5 } & & Sig. (2-tailed) & & 0,483 \\
\cline { 2 - 5 } & & N & 102 & 102 \\
\cline { 2 - 5 } & Q1134 & Correlation Coefficient & 0,070 & 1,000 \\
\cline { 2 - 5 } & & Sig. (2-tailed) & 0,483 & 106 \\
\cline { 2 - 5 } & & N & 102 & \\
& & & & \\
\end{tabular}

Figure 7 - Correlation between present and intended intensity according to Spearman

The correlation according to Spearman yields an only small correlation between Q1134 and Q1137, which is not significant. Thus, it cannot be assumed that the number of present cooperation considerably influences the intended intensity. In other words, if cooperation experience is measured by means of the number of cooperative arrangements a company is participating in, $\mathrm{H} 2$ does not hold. results.

In the next step, we carried out a correlation analysis including Q1136 and Q1137. Figure 8 shows the

\begin{tabular}{|c|c|l|r|r|}
\hline \multicolumn{5}{|c|}{ Correlations } \\
\hline \multirow{4}{*}{ Spearman's rho } & \multicolumn{1}{c|}{ Q1136 } & \multicolumn{1}{c|}{ Q1137 } \\
\cline { 2 - 5 } & Q1136 & Correlation Coefficient & 1,000 & 0,399 \\
\cline { 2 - 5 } & & Sig. (2-tailed) & & 0,000 \\
\cline { 2 - 5 } & & N & 98 & 98 \\
\cline { 2 - 5 } & Q1137 & Correlation Coefficient & 0,399 & 1,000 \\
\cline { 2 - 5 } & & Sig. (2-tailed) & 0,000 & 102 \\
\cline { 2 - 5 } & & N & 98 & \\
\hline
\end{tabular}

Figure 8 - Correlation between present and intended intensity according to Spearman ${ }^{3}$

\footnotetext{
${ }^{3}$ Applying the Komologorov-Smirnoff test to Q1134, Q1136, and Q1137, we saw that a Normal distribution cannot be assumed. for either variable
} 
We obtain a medium range correlation, which is highly significant. What exactly does this mean? First, there is a significant influence of the present intensity on the intended one. Second, the corresponding correlation is not very high, i.e. the intensity of current cooperation is not exactly mirrored in the intended intensity. To get more insight, we cross tabled the data gathered for Q1136 and Q1137.

\begin{tabular}{|c|c|c|c|c|c|c|}
\hline \multicolumn{7}{|c|}{ Crosstabulation } \\
\hline & & \multicolumn{5}{|c|}{ Q1136 } \\
\hline & & 1 & 2 & 3 & 4 & Total \\
\hline \multirow{5}{*}{$\frac{\hat{m}}{\bar{\sigma}}$} & 1 & 12 & 4 & 1 & 0 & 17 \\
\hline & 2 & 20 & 13 & 6 & 5 & 44 \\
\hline & 3 & 2 & 8 & 5 & 0 & 15 \\
\hline & 4 & 4 & 8 & 4 & 6 & 22 \\
\hline & Total & 38 & 33 & 16 & 11 & 98 \\
\hline
\end{tabular}

Figure 9 - Crosstabulation of Q1136 and Q1137

As figure 9 shows, companies currently cooperating at intensities 1 or 2 tend to higher intensities for future cooperation. For category 1, only 12 SME strive - again - for this level, but 26 (i.e. about $68 \%$ ) intend to cooperate with higher intensity. We obtain similar results for level 2: out of 33 cooperating SME, only 4 wish to decrease the intensity of cooperation, 13 intend to stay on the same level but 16 - about 50\% - strive for higher intensity in future. For SME on level 3 one can see that nine companies tend to partnering at the same or at the highest level. Finally, six out of eleven SME cooperating on level 4 intend to stay at the highest level. Summing up these considerations, one can argue that there is evidence for cooperating SME intensifying the intensity of cooperation.

In order to investigate Hypothesis 2 we can also use some results from the previous analysis for $\mathrm{H} 1$. According to Table 3, for companies already involved in cooperation stepwise regression indicates that only one variable has predictive power, i.e. Q1136. The same is true for companies which do cooperate and are assigned to the industry main sector (see table 4). The picture for SME belonging to the services main sector is not that clear as the stepwise regression model identifies another variable showing predictive power. Having a look at the standardized beta coefficients of both predictors, the importance of Q1139_6 is slightly higher as compared to Q1136. So with respect to companies already cooperating there is evidence for motivation related variables playing a rather small role when explaining the intended intensity of future cooperation. On the other hand, the results show that the present level of cooperation explains to a certain extent the variance of the independent variable.

Summarizing these arguments one can say: experience does matter; nevertheless, looking closer on this statement is useful. One can see that experience in terms of the sheer number of current cooperation seem to play no crucial role for the intended intensity. If we define experience as positive or negative perception of the current cooperation's intensity we get evidence that there is an influence. This impact seems to be extending in nature, i.e. owner-managers whose companies are involved in cooperation generally aim at cooperating at least at the same level as in the past. This is especially true for SME engaged in cooperation characterized by intensity levels 1 and 2. These findings strongly support $\mathrm{H} 2$ in terms of the role of the present intensity; however, the number of cooperation has a rather weak impact.

\section{CONCLUSIONS AND IMPLICATIONS}

This paper tried to shed some light on whether an owner-manager's intentions on the intensity of future cooperation depend on his attitudes toward motivations for cooperation. We assumed that the manager's assessment of motivations for cooperation does influence this intensity. Further, we suggested, that also the experience with current cooperation have an impact on the future intended intensity. Our explorations confirmed these assumptions to a certain extent. First, there seems to be indeed an influence of motivation related variables on intensity. For the sample as a whole, this relationship is rather limited, but focusing on certain groups of the sample, we find much stronger evidence for our hypothesis. Among the variables which proved to have predictive power were Q1139_4, 
Q1139_10, and Q1139_1. The first variable refers to know-how exchange and has a negative coefficient. Ownermanagers seem to be rather reluctant to intense cooperation when they pursue knowledge-related purposes. Probably they wish to profit from know-how exchange without establishing closer relationships to other companies. As for the second variable, i.e. join forces to withstand large companies, there is a positive influence. The more important this goal for an owner-manager is, the more willing he seems to be to build up closer relations to external partners. One can argue that owner-managers are aware that, in order to withstand the sometimes overwhelming resources of large companies, more than a mere exchange of experiences is required. Rather, higher forms of cooperative arrangements, such as virtual companies, seem to be necessary. Lastly, for a sub-group of the sample, also extending the distribution area showed predictive power at a negative coefficient. It seems that owner-managers belonging to this group wish to make use of more and wider sales channels, but not by means of intense cooperation but rather by instruments of lower intensity such as common activities. Thus, one can see that certain motivations seem to render owner-managers more willing to establish closer relations to external partners, whereas for other motivation aspects, cooperation of lower intensity appears to be sufficient.

With respect to experience, we can of course only examine owner-managers whose companies are already involved in cooperation. It turned out that the number of cooperations a company is participating in does not have a significant influence on the intended intensity. Thus, owner-managers seem to distinguish between quantity on the one hand and quality in terms of intensity on the other. The sheer number of links to external partners may influence their willingness to participate in future cooperation, but when it comes to discuss the level of future cooperation, experience measured in other categories becomes more relevant. One such category clearly is the intensity of current cooperative arrangements. Interestingly, there seems to be a tendency of - compared to current cooperation - higher intensities for future arrangements. Most respondents intend to cooperate at least at the same level as in the past. For companies currently operating at levels 1 and 2, most owner-managers strive for higher intensities in the future. Looking again at figure 4 one could argue that most of the interviewees were rather satisfied with the lower forms of intensity. Based on these more or less positive experiences, they seem to feel themselves more able to participate in cooperations of higher intensity, cooperations which generally require more input in terms of time, resources, and the willingness to abstain from complete control of decision making.

As for managerial implications, one can say that cooperation which is set up for pursuing certain motivations is likely to have a specific form. This should be kept in mind when new cooperations are about to be founded. In order to define realistic goals and set up a stable cooperative arrangement, partners or third person parties such as economic development agencies should carefully assess the motivations of the owner-managers involved in the project. This would allow for the search of partners with similar interests, not only in terms of goals, but also with respect to the organizational design of the cooperation, thereby contributing to the arrangement's stability. On the other hand, the impact motivations have on the intended intensity makes it somewhat easier to define the rules for running the cooperation, as it is more apparent now what kind of interaction owner-managers are willing to accept in order to follow a certain purpose of their companies.

When talking to potential partners, one should be aware of the cooperation experiences these ownermanagers and their companies have. The sheer number of cooperations a SME is involved in is not an adequate indicator for an owner-manager's willingness to cooperate more intensely than a decision maker from a company with very little current cooperation. On the other hand, it can be expected that very often an owner-manager would consider cooperating on at least the same level as he did in the past. Owner-managers' experiences with the intensity aspect make them interesting partners as they are clearly aware of the consequences cooperation at a certain level entails. Furthermore, those who had rather positive experiences tend to be more willing to engage in higher levels of cooperation. In fact, some of them do seek arrangements with higher intensity so, once more, similarities in terms of organizational aspects can be taken into account and thus increase the future cooperation's stability.

Of course, the study has some limitations. First, the empirical data refer to Mexico only. To get an impression of whether owner-managers from other countries - especially North America, Europe, and Asia - show similar characteristics, further research is necessary. Next, it was rather difficult to find results valid for the sample as a whole. It proved to be much more fruitful to explore certain sub-groups of the sample; these were distinguished by cooperation experience and the industry they occupy. Further differentiation may lead to additional results. Also, 
the regression analyses computed included for certain sub-groups rather small numbers of respondents. Although the F statistic for each analyzed model stated that the null hypothesis for the corresponding model can be rejected which is why it can be assumed that the coefficients in the population are distinct from 0 - it seems to be necessary to check the findings against larger sample sizes.

Manuel Haug is research assistant at Albstadt-Sigmaringen University in the Department of Business Administration and Engineering. He holds a degree in Business Administration from the Catholic University of Eichstaett, Germany.

His research work comprises two areas of interest: while he deals on the one hand with logistics management and simulation, his major research interest is cooperation among Small and Medium-sized Enterprises (SME). For the latter, the special focus is on linking these research fields with managerial cognition theory.

Lutz Sommer is Professor at Albstadt-Sigmaringen University in the Department of Business Administration and Engineering. He studied in Germany (Berlin Institute of Technology / University of Hagen ) and Poland ( University of Gdansk ) and holds a BEng / MEng in Engineering and a BSc / MSc in Business Administration and Engineering as well a $\mathrm{PhD}$ in economics.

His research activities deal with the internationalization activities of Small and Medium-Sized Enterprises (SME). In particular, the focus is on the influence of socio-psychological factors on the owner-managers' decision making processes in terms of internationalization.

\section{REFERENCES}

1. $\quad$ Acs, Z.J./Preston, L. (1997: Small and Medium-Sized Enterprises, Technology, and Globalization: Introduction to Special Issue on Small and Medium-Sized Enterprises in the Global Economy; in: Small Business Economics 9, 1997, pp. 1-6

2. Alizadeh, Y. (1998): Small Ethnic Enterprise Networks; Conference Paper, International Council for Small Business (ICSB) Conference, Singapore, June 1998

3. Audretsch, D.B./Turik, A.R. (2001): What's new about the New Economy? Sources of Growth in the Managed and Enterpreneurial Economies; in: Industrial and Corporate Change 10, No. 1 (2001), pp. 267315

4. $\quad$ Beck, T./Demirguc-Kunt, A./Levine, R. (2005): SME, Growth, and Poverty: Cross-Country Evidence; in: Journal of Economic Growth 10, No. 3 (2005), pp. 199 - 229

5. Beecham, M. A./Cordey-Hayes, M. (1998): Partnering and Knowledge Transfer in the U.K. Motor Industry; in: Technovation 18, No. 3 (1998), pp. 191-205.

6. $\quad$ Bruderl, J./Preisendorfer, P./Ziegler, R. (1992): Survival Chances of Newly Founded Business Organizations; in: American Sociological Review 57, No. 2 (1992), pp. 227-242.

7. Brunetto, Y./Farr-Wharton, R. (2007): The Moderating Role of Trust in SME Owner/Managers' DecisionMaking about Collaboration; in: Journal of Small Business Management 45, No. 3 (2007), pp. 362 - 387

8. Dodd, S. D./Jack, S./Anderson, A.R. (2002): Scottish Entrepreneurial Networks in the International Context; in: International Small Business Journal 20, No. 2, pp. 213-219

9. Elo, M. (2003): National Culture and its Impact on Trust and Cooperation in International Business Networks: Some Empirical Evidence from a Greek-Finish Business Network; Conference Paper, IMP Annual Conference, Lugano / Switzerland, 2003

10. ENSR (2003): ENSR Enterprise Survey 2003 - Co-operation among SME (Part A), Zoetermeer

11. European Commission (1998): Enhancing European Competitiveness, Report of the Competitiveness Advisory Group, European Commission, Brussels, 1998.

12. Eurostat (2006): KMU und Unternehmergeist in der EU - Statistik kurz gefasst - Industrie, Handel und Dienstleistungen, Luxembourg

13. Fink, M./Kraus, S. (2007): Mutual Trust as a Key to Internationalization of SMEs; in: Management Research News 30, No. 9 (2007), pp. 674 - 688 
14. Fishbein, M./Ajzen, I. (1975): Belief, Attitude, Intention, and Behavior: an Introduction to Theory and Research; Reading

15. Fröhlich, E.A./Pichler, J.H. (1998): Entrepreneurial Profiles and Strategies for the Larger Market; in: Haahti, A./Hall, G./Donckels, R. (1998 Eds.): The Internationalization of SMEs: the Interstratos Project, pp. 63 - 80, London

16. Hartl, R. (2003): Industry, Enterprise, and behavioral predictors for inter-firm cooperation in Small and Medium-sized Enterprises, Working Paper DePaul University/St. Gallen University

17. Hofstede, G. (1980): Culture's Consequences: International Differences in Work-related Values, Beverly Hills

18. Hofstede, G. (1991): Cultures and Organizations: Software of the Mind, Bershire

19. Human, S.E./Provan, K.G. (1997): An Emergent Theory of Structure and Outcomes in Small-Firm Strategic Manufacturing Networks; in: Academy of Management Journal 40, No. 2 (1997), pp. 368 - 403

20. Jarillo, C.J. (1989): Entrepreneurship and Growth: The strategic use of external Resources; in: Journal of Business Studies 19 (1989), pp. 411-432

21. Kirby, D.A./Kaiser, S. (2003): Joint Ventures as an internationalization strategy for SME; in: Small Business Economics 21, No. (2003), pp. 229-242

22. Kocak, A./Edwards, V. (2005): Independence and Co-operation Among Small Businesses - The Case of the Turkish Shotgun Industry in a Period of Recession; in: International Journal of Entrepreneurial Behaviour \& Research 11, No. 3 (2005), pp. 186 - 200

23. Kühlmann, T.M. (2004): Vertrauen und Kontrolle in internationalen Unternehmenskooperationen; in: Maier, J. (Ed): Vertrauen und Marktwirtschaft - Die Bedeutung von Vertrauen beim Aufbau marktwirtschaftlicher Strukturen in Osteuropa, forost Arbeitspapier Nr. 22, pp. 67 - 82

24. Legohérel, P./Callot, P./Gallopel, K./Peters, M. (2004): Personality Characteristics, Attitude Toward Risk, And Decisional Orientation of the Small Business Entrepreneur: A Study of Hospitality Managers; in: Journal of Hospitality \& Tourism Research 28, No. 1 (2004), pp. 109 - 120

25. Lohrke, F.T./Kreiser, P.M./Weaver, K.M. (2006): The Influence of Current Firm Performance on Future SME Alliance Formation Intentions: A Six-country Study; in: Journal of Business Research 59 (2006), pp. $19-27$

26. Marino, L./Strandholm, K./Steensma, H.K./Weaver, K.M. (2002): The Moderating Effect of National Culture on the Relationship Between Entrepreneurial Orientation and Strategic Alliance Portfolio Extensiveness; in: Entrepreneurship Theory and Practice 26, No. 4 (2002), pp. 145 - 160

27. Moore, D. P.,/Moore, J.L. (1999): Networking — an Interactive Approach to Threshold Management; Conference Paper, United States Association for Small Business and Entrepreneurship (USASBE) Conference, San Diego / USA, January 1999

28. OECD (2002): Small and Medium Enterprise Outlook, Paris

29. Oughton, C./Whittman, G. (1997): Competition and Cooperation in the Small Firm Sector; in: Scottish Journal of Political Economy 44, No. 1 (1997), pp. 1-30

30. Narayanan, V.K. (2000): Managing technology and innovation for competitive advantages, New Jersey

31. Perlitz, M./Seger, F. (2003): Internationalisierung durch Kooperation; in: Zentes, J./Swoboda, B./Morschett, D. (2003 Eds.): Kooperationen, Allianzen und Netzwerke, Wiesbaden, pp. 515 - 542

32. Pichler, J.H./Voithofer, P. (2000): Patterns of SME Cooperation, Strategic Alliances and Networking; Conference Paper; ICSB World Conference, Brisbane / Australia, June 2000

33. Pollnac, R.B./Carmo, F. (1980): Attitudes toward Cooperation among Small-Scale Fishermen and Farmers in the Azores; in: Anthropological Quarterly 53, No. 1 (1980), Special Issue: Maritime Anthropology, pp. 12-19

34. Ringlstetter, M. (1997): Organisation von Unternehmen und Unternehmensverbindungen, Munich

35. Renzulli, L. A./Aldrich, H./Moody, J. (2000): Family Matters: Gender, Networks, and Entrepreneurial Outcomes; in: Social Forces 79, No. 2 (2000), pp. 523-546

36. Rus, A./Iglic, H. (2005): Trust, Governance, and Performance: The Role of Institutional and Interpersonal Trust in SME Development; in: International Sociology 20, No. 3 (2005), pp. 371 - 391

37. Schermerhorn, J.R. (1975): Determinants of Interorganizational Cooperation; in: Academy of Management Journal 18, No. 4 (1975), pp. 846-856 
38. Schreyer, P. (1996): SME and Employment Creation: Overview of Studies in OECD Member Countries, STI Working Papers 1996/4, Paris: OECD

39. Silverman, B.S./Baum, J.A.C. (2002): Alliance-based competitive dynamics; in: Academy of Management Journal 45, No. 4 (2002), pp. 791-806

40. Sommer, L./Reiband, M. (2006): Internationale Unternehmenskooperationen im Mittelstand Mexikanische KMU, Working Paper, Albstadt-Sigmaringen University

41. Steensma, H.K./Marino, L./Weaver, K.M. (2000): Attitudes Toward Cooperative Strategies: A Crosscultural Analysis of Entrepreneurs; in: Journal of International Business Studies 31, No. 4 (2000), pp. 591609

42. Street, C.T./Cameron, A.-F. (2007): External Relationships and the Small Business: A Review of Small Business Alliance and Network Research; in: Journal of Small Business Management 45, No. 2 (2007); pp. $239-266$

43. Volery, T./Mensik, S. (1998): The Role of Trust in Creating Effective Alliances: A Managerial Perspective; in: Journal of Business Ethics 17, No. 9/10 (1998), pp. 987-994.

44. Wattanapruttipaisan, T. (2003): Four Proposals for Improved Financing of SME Development in ASEAN; in: Asian Development Review, vol. 20, no. 2, pp. 66-104

45. Weaver,K. M./Dickson, P. (1997): Environmental Determinants and Individual Level Moderators of Alliances; in: Academy of Management Journal 40, No. 2 (1997), pp. 404-425

46. Yin, X. (2005): Information and Communication Technology (ICT) for development of small and mediumsized exporters in East Asia: China, United Nations Development Programme, New York

47. Young, C. E./Olk, P. (1997): Strategic Alliances: The Role of Individual Discretion and Personal Attachments in the Decision to Continue; Conference paper, Western Decision Sciences Institute Conference, Honolulu /USA 